\title{
An analysis of reproducibility of DAI and IOTN indexes in a Brazilian scene
}

\author{
Análise da reprodutibilidade dos índices DAI e IOTN \\ em um cenário brasileiro
}

Rejane Bezerra de Lima ${ }^{1}$

Ângela Cristina Pinto de Paiva ${ }^{1}$

Arthur Costa Rodrigues Farias ${ }^{2}$

Kenio Costa Lima ${ }^{1}$

${ }^{1}$ Departamento de Odontologia Preventivae Social, Faculdadede Odontologia, U niversidade Federal do Rio Grandedo Norte. Av. Salgado Filho 1787, Lagoa N ova. 59056-000 Natal RN. rejane_lima@hotmail.com 2 Universidade Federal da Bahia.
Abstract The aim of this study was to evaluate the ability of the indexes DAI and IOTN in predicting the need of orthodontic treatment based in one property: reproducibility. The index DAI was developed in USA in 1989 and can identify 10 occlusal alterations that result, mathematically, in scores, with weights based in its relative importance according with the judgment of laypeople. The IOTN was developed in England also in 1989 and incorporates an aesthetic component $A C$ and a component of dental health DHC. The AC component consists on a scaleillustrated with 10 photos which had been divided in bands of degrees in accordance with a hierarchic scale and classifies the patients in degrees of treatment needed. The instruments of collection of the data were: plastic rule of DHC component and an aesthetic visual scale of component AC praised for the IOTN and one periodontal OM S probe praised for DAI. The sample was composite by 60 patients. The results indicated that both indexes were highly reproducible in accordance with Pearson and Spearman coefficients, which were strengthened by t-tests of Student and Wilcoxon, respectively. The correlation results between the examiners had varied between $r=0.85$ and $r=1.00$. Key words Reproducibility, DAI, IOTN, Orthodontic treatment
Resumo 0 objetivo deste estudo foi avaliar a capacidadedosíndicesDAI eIOTN em predizer a necessidade de tratamento ortodôntico baseado em uma propriedade: reprodutibilidade. 0 índiceDAI foi desenvolvido nosEstados U nidos (1989) eidentifica dez alterações oclusais que resultam, matematicamente, em escores, com pesos específicos baseados em um determinado grau de importância de acordo com o julgamento de pessoas leigas. o IOTN foi desenvolvido na Inglaterra ( 1989) e possui um componente estético - AC - eum componente dentário - DHC. 0 componente AC consisteem uma escala ilustrada com 10 fotos as quais representam um escala hierárquica de necessidade de tratamento ortodôntico. Os instrumentos para col eta de dados foram uma régua plástica do componente DH C ea escala visual do componente AC para o índice IOTN; sonda periodontal da OM Sutilizada no índiceDAI . A amostra foi composta por sessenta pacientes. Os resultados indicam que ambos osíndices foram altamente reprodutíveis de acordo com os coeficientes de Pearson e Spearman. Para esses coeficientes, foram utilizados, respectivamente, teste $t$ de Student e Wilcoxon. 0 resultado de correlação entre os examinadores variou entre $r=0,85$ e $r=1,00$.

Palavras-chave Reprodutibilidade, DAI, IOTN, Tratamento ortodôntico 


\section{Introduction}

Nowadays, the existing health services are deficient in supplying basic oral health attention to the great majority of the population and this number becomes even more reduced when it is considered oral specialized service. Regarding to occlusal problems, wherethere is a need of doing an intervention orthodontic, thissituation is even moreserious. In fact, it is becoming a reality more distant to patients of lower income ${ }^{1}$.

A way to outline such problems would be to know the epidemiologic situation of a certain population. Then, services could be planed and executed with justness to overcometheindiscriminate service for free demand or it demands drug addict ${ }^{2}$. Therefore, some indexes that affect malocclusion at a collective level were developed. Based on scientific parameters, such indexes allow an evaluation of the need for treatment of a certain population group, identifying the individuals with more treatment needed, it could be executed in a simple way and allowing a fairer access to the services ${ }^{3-5}$.

Because of aspects as the great variety of occlusal indexes, variables related to the size of the sample, to the appraised scholars' socioeconomic factor among other, it exists in the literature many studies with specific characteristics that it turn difficult the comparison not only in relation to the malocclusion prevalence ${ }^{3}$ found as in relation to the reproducibility ${ }^{6-8}$ to the consistence $e^{8-11}$ and to the benefits brought by the orthodontic treatment ${ }^{12}$.

Therefore, in agreement with the problems al ready described, Emrich et al..$^{13} \mathrm{em}$ phasized that the explanation to the great variability of the results of studies on the prevalence of the malocclusion was the unanimity absence among the professionals than it would bereally an malocclusion and, therefore, only for them the classification of Angle ${ }^{14}$ would reach that homogeneity degree.

Due to the availability of several indexes and taking into account their characteristics, it is evident the need for accomplishment of astudy that evaluates the reproducibility and the capacity of diagnostic prediction of the need of orthodontic treatment ${ }^{15}$.

Then, comparisons were carried out among cases diagnosed thoroughly by two examiners making use of two indexesused, DAI ${ }^{16}$ and IOTN ${ }^{17}$.

In this way, the objectives of this work were: to evaluate the reproducibility of IOTN Dental Index and Aesthetic Component of $\mathrm{H}$ ealth and of the Index of Dental Aesthetics, as established by $\mathrm{OM} \mathrm{S}^{18}$; to compare the two indexes regarding thereproducibility; to comparethereproducibility of the components AC and DHC of IOTN.

\section{Material and method}

Thereproducibility of theindexes DAI and IOTN that consists of the capacity of an index in expressing the same values obtained when an individual is re examined by the same examiner or by different examiners, it was evaluated. With this purpose, 60 scholars with the age 12 yearold wereappraised by two trained examiners and gagged. To start the data collection, explanatory letters were given to the director of the school with intention of asking permission so that this study could be developed. Besides, parents of each selected student signed a term of consent to carry out the study approved by ethic committee.

Used indexes

Index of Orthodontic Treatment Need (IOTN)

This index has an Aesthetic component (AC) and one of dental health (DHC).

The $\mathrm{DHC}$ registers, through a plastic ruler extolled by the index, the occlusal characteristics of an malocclusion that harm the teething and adjacent structures. There are five levels, from the Degree 1 (there is no need for treatment) up to the Degree 5 (there is a great need for treatment). This index serves as basic guide for an impartial judgment of the malocclusion. There are two manners of evaluating the data from DHC index. Thefirst onetakes into account only the degree (from 1 to 5 ), and the second indicates the cause for the categorization at this level. Each characteristic is represented by a letter besides the number of the Degree, being like this, $5 a$ for larger overjet than $9 \mathrm{~mm}$.

The aesthetic component (AC) consists of a scale of ten colored pictures showing different levels of beauty of the smiles which was the same adopted by Evans and Shaw ${ }^{19}$ denominated of SCAN. The objective of the scale is to find a similar smile or with level of equivalent severity to the individual appraised, placing the smilein relation to the number 1 that represents the most attractive smile and the number 10 that it represents the less attractive smile ${ }^{16}$. 
Dental Aesthetic Index (DAI)

Theindex of Dental Aesthetics is constituted by three groups of different conditions, which are: teething (dental loss), space (crowding, spacing, diastema $(\mathrm{mm})$, previous maxillary crowding $(\mathrm{mm})$ and crowding previous mandibular $(\mathrm{mm})$ ) and occlusion (maxillary overjet and mandibular $(\mathrm{mm})$, vertical open bite previous $(\mathrm{mm})$ and relationship molar) ${ }^{17}$.

Data evaluation

IOTN index

The component of dental health of this index can be subdivided in three stages of severity according to the need of orthodontic treatment. If the patient is framed within the degrees 1 and 2 is considered to be without or little need for orthodontic treatment. At the degree 3 is considered to be with moderate need of orthodontic treatment and at the degrees 4 and 5 is considered to be with severe need of orthodontic treatment.

In the same way, this criterion can be applied to the aesthetic component of this index. The degrees from 1 to 4 are related to patients without or little need for orthodontic treatment, the degrees 5,6 and 7 with moderate need of orthodontic treatment and the degrees 8,9 and 10 are related to severeneed for orthodontic treatment.

DAI index

The final scores of theDAI index are obtained mathematically through which some of their components are multiplied by their respective weights. The final result is then added to the constant of an equation of value 13 . The resulting sum represents the DAI score.

The severity of the malocclusion within a population is classified based on the score obtained through the evaluation of the characteristics occlusal that results in the final score. Patients with smaller scores than 25 are considered with any or littleneed. Scores between 26 to 30 are considered with elective treatment indication and scores between 31 to 35 or larger than 36, are considered with treatment indications highly desirable and indispensable, respectively.

To evaluate and to comparethe degree of orthodontic treatment need of the cases analyzed, according with both indexes, the patients who were considered without the need for orthodontic treatment, according to DAI, presented scores up to 25 , with moderate need of treatment with scores of 26-35 and with severe treatment need with larger scores than 36 .
Statistical hypotheses

$\mathrm{H}_{0}=$ Both indexes are reproducible

$\mathrm{H}_{1}=$ Both indexes are not reproducible

$\mathrm{H}_{0}=$ Theindex DAI has better reproducibility than IOTN

$\mathrm{H}_{1}=$ The index DAI doesn't have better reproducibility than IOTN

$\mathrm{H}_{0}=$ The component DHC of IOTN is more reproducible than $A C$

$\mathrm{H}_{1}=$ The component DHC of IOTN is not more reproducible than $A C$

\section{Statistical analysis}

To evaluate the reproducibility it was verified the agreement among the data obtained by the examinersin relation to DHC-IOTN, AC-IOTN, to the characteristics of the DAI, the patients' $A C$ and the positive or negative answers of them when questioned by each examiner if there was a need for orthodontic treatment.

In order to achieve this goal, it was necessary to separate the quantitative variables with and without normal distribution and the qualitative ones (categories and strips) to the statistical tests could be used in an appropriate way.

The statistical tests applied in this study will be described for each type of variable with their respective functions to a significance level of $5 \%$

a) Quantitative variables with normal distribution: Pearson Correlation coefficient and $t$ test of Student

b) Quantitative variables without normal distribution: Spearman Correlation coefficient and Wilcoxon test

c) Qualitative variables in categories: kappa Coefficient and Wilcoxon test or proportions test

d) Qualitative variables in strips: kappa Coefficient and Chi-square test or Fisher test.

\section{Results}

The data that presented a normal distribution, maxillary overjet and the final data of the DAI were very well correlated among the examiners $(r=0.96)$ in accordance with the Pearson correlation coefficient. According to the t test of Student, there was not statistical significant difference ( $p>0.05$ ) among the averages obtained by the two examiners. In other words, the averages obtained were similar (Table 1). 
The data that did not present a normal distribution also presented a high correlation according to the Spearman correlation coefficient, being in a decreasing order of correlation: overjet mandibular and open bite $(r=1.00)$, diastema $(r=0.997)$, maxillary crowding $(r=0.947)$, teething $(r=0.92)$, crowding mandibular $(r=0.852)$.

The results obtained from the Wilcoxon test corroborated with the data obtained by the $t$ test and al so did not demonstrate significant difference between the medium obtained for these characteristics (Table 2).

Theaccordanceobtained among the categorical data were al so high (Table3) being presented in decreasing order of Kappa correlation: the patient's opinion $r=0.986$, subcategories of DHC (letter) $r=0.936$, because they are easier to agree than the number of DHC, DHC (numeric value) $r=0.889, A C$ of the professional $r=0.839, A C$ of the patient $r=0.690$. The Kappa correlation among the components of the DAl also in decreasing order were: crowding $r=0.905$, molar relationship $r=0.866$ and spacing $r=0.850$. In order to evaluate if there was significant difference among the results obtained by the two examiners, the Wilcoxon test was used, except for the patient's opinion. For all these variables, the

Table 1. Correlation Pearson Coefficient and the $p$ value according to the test of Student for variables with normal distribution. Natal (RN), 2006.

\begin{tabular}{lcl}
\hline \multicolumn{1}{c}{ Variable } & Pearson coeficient & $\mathrm{p}$ value \\
\hline Final DAI & $\mathrm{r}=0.96$ & $\mathrm{p}=0.34 * *$ \\
Maxillary Overjet & $\mathrm{r}=0.96$ & $\mathrm{p}=0.68 * *$ \\
\hline
\end{tabular}

*Sig.; *NS.

Table 2. Correlation Spearman Coefficient and the $p$ value according to the Wilcoxon test for variables without normal distribution. Natal (RN), 2006.

\begin{tabular}{lrr}
\hline \multicolumn{1}{c}{ Variable } & $\begin{array}{c}\text { Spearman } \\
\text { coeficient }\end{array}$ & $\mathrm{p}$ value \\
\hline Overjet mandibular & $\mathrm{r}=1.00$ & $\mathrm{p}=1.0 * *$ \\
Open bite & $\mathrm{r}=1.00$ & $\mathrm{p}=1.0^{* *}$ \\
Diastema & $\mathrm{r}=0.997$ & $\mathrm{p}=0.08$ ** \\
Maxillary crowding & $\mathrm{r}=0.923$ & $\mathrm{p}=0.10^{* *}$ \\
Teething & $\mathrm{r}=0.852$ & $\mathrm{p}=0.31^{* *}$ \\
M andibular crowding & & \\
\hline
\end{tabular}

*Sig.; *NS. value of $p$ was not statistically significant and, therefore, there has no difference among the two examiners. For the patient's opinion, the test of proportions was used because they are considered to be objective answers and also, the value of $p$ did not show significant difference between the two examiners.

The degree of need of orthodontic treatment according to the two examiners was evaluated by strips (SNT, NM T and NST) in accordance with each index (Table 4). In order to evaluate the distribution of the data among the strips of the indexes DAI, DHC-IOTN, AC-IOTN and the patient's AC, the chi-square or Fisher test was carried out. The results indicated that the value $p=0,00$ was statistically significant for both indexes, evidencing that a significant differenceexisted. Therefore, the distribution of the data obtained among the examiners was not statistically the same. The classification of thestrips by scores can give this type of result.

Table 3. Correlation Kappa Coefficient of the categorical data and the $p$ value according to the Wilcoxon tests or proportions. Natal (RN), 2006.

\begin{tabular}{lrr}
\hline \multicolumn{1}{c}{ Variable } & $\begin{array}{c}\text { Kappa } \\
\text { coeficient }\end{array}$ & p value \\
\hline Patient opinion & $r=0.986$ & $0.801^{* *}$ \\
DHC letter & $r=0.936$ & $0.655^{* *}$ \\
DHC numeric & $r=0.889$ & $0.157^{* *}$ \\
AC of the professional & $r=0.839$ & $0.944^{* *}$ \\
AC of the patient & $r=0.690$ & $0.657^{* *}$ \\
DAI- crowding & $r=0.905$ & $0.414^{* *}$ \\
DAI- molar relationship & $r=0.866$ & $0.655^{* *}$ \\
DAI- spacing & $r=0.850$ & $0.059^{* *}$ \\
\hline
\end{tabular}

*Sig.; **NS.

Table 4. Correlation Kappa coefficient and the $p$ value according to the chi-square test of the degree for the need of orthodontic treatment. Natal (RN), 2006.

\begin{tabular}{lll}
\hline \multicolumn{1}{c}{ Variable } & $\begin{array}{c}\text { Kappa } \\
\text { coeficient }\end{array}$ & p value \\
\hline DHC & $r=0.86$ & $p=0.00 *$ \\
AC & $r=0.84$ & $p=0.00 *$ \\
DAI & $r=0.78$ & $p=0.00 *$ \\
AC of the patient & $r=0.65$ & $p=0.00 *$ \\
\hline
\end{tabular}

*Sig.; **NS. 
The frequency of the data obtained by the examiners in relation to the degrees of need for orthodontic treatment in agreement with the indexes DAI, DHC-IOTN , AC-IOTN and the patient'sAC, can be visualized in the Figures 1,2 , and 3 .

Regarding thefrequency of thescores of each index, the results indicated that the degrees 4 and 5 regarding severe need (NST) were the most

Exam. 1 - SNT

Exam. 2 - SNT

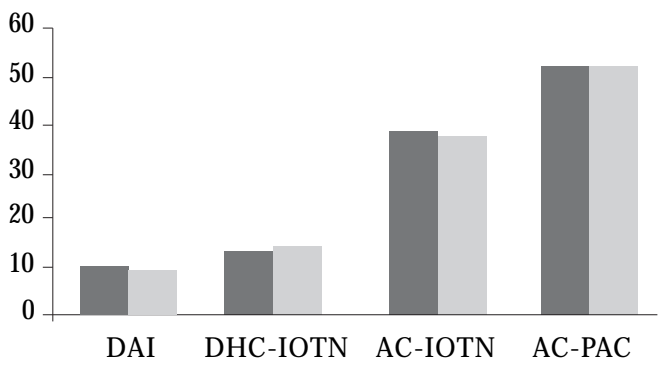

Figure 1. Distribution of the data obtained by the examiners related to cases without the need for orthodontic treatment according to the indexes DAI, DHC-IOTN, AC-IOTN and the AC of the patient. $\mathrm{N}$ atal (RN), 2006.

Exam. 1 - SNT

Exam. 2 - SNT

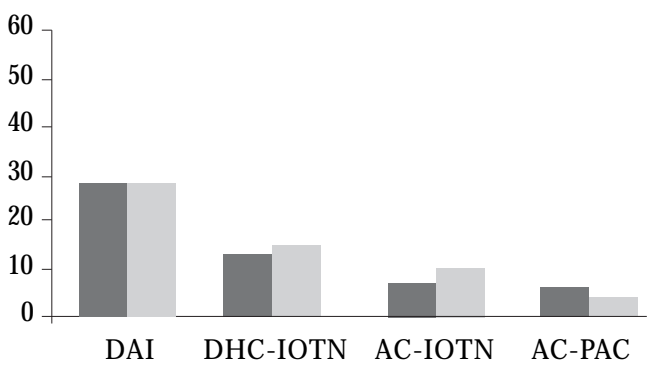

Figure 2. Distribution of the data obtained by the examiners related to cases with the need for moderate orthodontic treatment according to the indexes DAI, DHC-IOTN, AC-IOTN and the AC of the patient. $N$ atal $(R N), 2006$. frequent for the index DHC-IOTN (Figure 4), the degrees 2 and 4 for AC-IOTN (Figure 5) equivalent the without need of orthodontic treatment (SNT) and for the index DAI in the strip among 26-35 was the score 33 (moderate need of treatment) and in the strip among 36-100 the score 39 (severe need of orthodontic treatment) (Figure6).

Exam. 1 - SNT

Exam. 2 - SNT

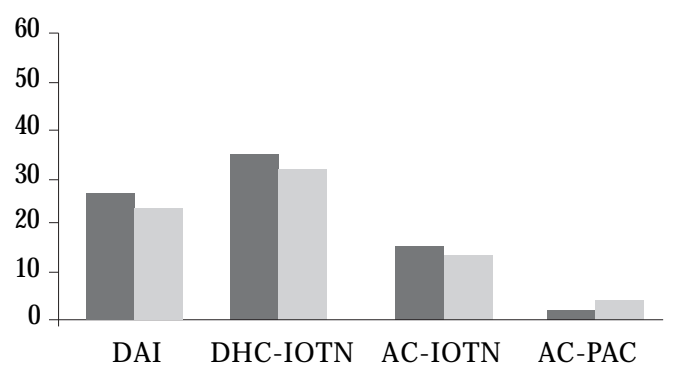

Figure 3. Distribution of the data obtained by the examiners related to cases without the need for severe orthodontic treatment according to the indexes DAI, DHC-IOTN, AC-IOTN and the AC of the patient. Natal (RN), 2006.

Exam. 1 - SNT

Exam. 2 - SNT

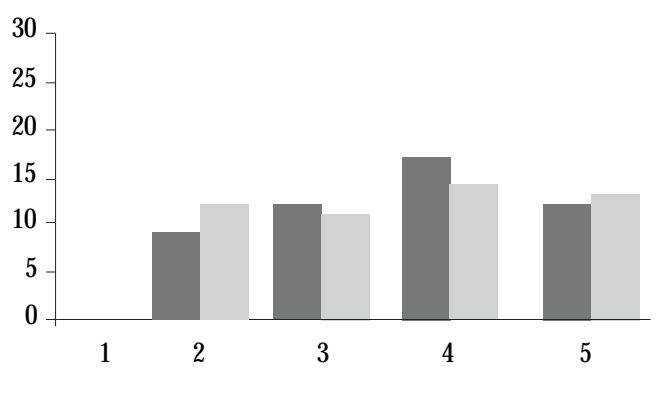

Figure 4. M ost frequent values according to the DHC-IOTN index. Natal (RN), 2006. 
Exam. 1 - SNT

Exam. 2 - SNT

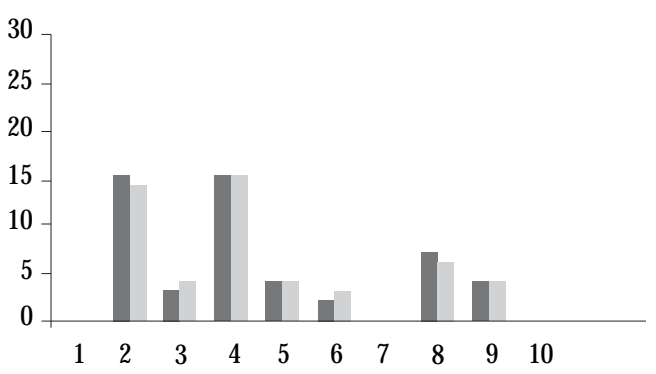

Figure 5. M ost frequent values according to the AC-IOTN index. Natal (RN), 2006.

Exam. 1 - SNT

Exam. 2 - SNT

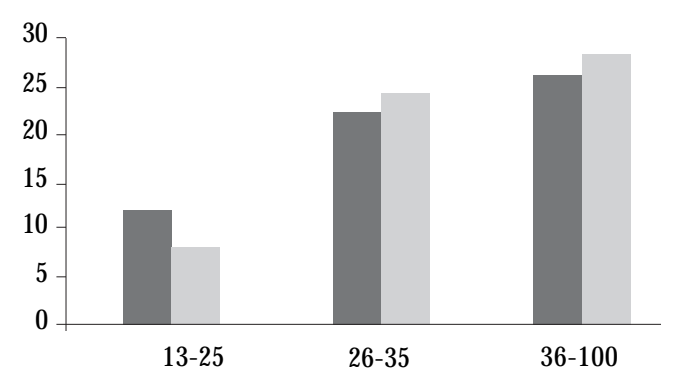

Figure 6. M ost frequent values according to the DAI index. Natal (RN), 2006.

\section{Discussion}

Based on the premise that the conventional orthodontic diagnosis is qualitative and, therefore, a descriptive procedurethat hinders a quantitative evaluation, many quantitative systems of evaluation of the malocclusion and of the need for orthodontic treatment have been developed during the last fifty years. Each index summarizes a group of characteristic occlusal that results in numeric values. For each one of these indexes a cut point exists below which the severity of the malocclusion is considered smaller than the need of orthodontic treatment and values above this point the cases are considered with need of orthodontic treatment. As a consequence, an index with cut point works as a diagnosis test ${ }^{8}$.

The correlation results obtained among the examiners were considered high, for the variables with and without normal distribution, in accordance with Eklund et $a^{20}$. They emphasize the difficulty of specifying a kappa value as a standard for an appropriate calibration. This is because the kappa value varies according to the total agreement and of the characteristics of the distribution. In addition, when evaluating if there was statistical difference among the results obtained by the examiners it was not observed any difference to the values of $p$ for DAI and IOTN.

Richmond et al. ${ }^{21}$ also proved the reproducibility of IOTN evaluating the consensus of opinions about the need for treatment within a group of 74 dentists, orthodontists and general practitioners. According to Otuyemi and N oar ${ }^{22}$, who evaluated the variability among the indexes DAI, OI, H M AR, there area high level of reproducibility and correlation among them.

Considering the categorical data, it can be observed that according to the tableIII, except for the patients' AC, the other data resulted in kappa values were considered high. In addition, when the value of $p$ is evaluated it was not observed significant difference between thetwo examiners.

Comparing with the other classification methods with IOTN and DAI it is important to emphasize some points. The Classification of Angle ${ }^{14}$ indicated to havelow reproducibility ${ }^{16}$ and it was proven useless to the analysis of the priority for treatment. For the epidemic use, the registration techniques described by Björk et al. ${ }^{23}$ areconsidered acceptable concerning the precision to identify the several aspects of the occlusion, in up to $80 \%$ of agreement. However, they do not evaluatethe priority for treatment. The attribution of weight to someaspects of theocclusion promotes a certain concern of feeling to give them a degree of severity, and then to prioritize the treatment. Several indexes were created with that principle ${ }^{24}$ 27. Perhaps, the great diversity of occlusal indexes is explained by some of them do not register a great variation of occlusal characteristics, to present a certain subjectivity degree, to be used with different objectives for which they were extolled, due to the great diversity of works that make impossible the comparison and evaluation of their reproducibility. As a consequence, theindexes DAI and IOTN present advantages because they have been extolled to evaluate the need of orthodontic treatment and be reproducible. 
The data obtained in this study were based on the results pointed out by Yeh et al. ${ }^{28}$, who indicated that the two indexes DAI and IOTN are capable to identify the patients' occlusal characteristics, despite of existing few studies that compare them objectively ${ }^{29,30}$. These indexes havesimilar objectives, however, with different applications. Although the index DAI seems to be easier to use, it does not evaluate some occlusal characteristics, such as: cross bite, deep overbite and deviation of medium line ${ }^{22}$. Another aspect to be taken into account is that the margin of error of the DAI is larger, sincethe occlusal characteristics are measured with the probe periodontal and they can reflect great alterations, when the corresponding weights areadded to the measures. The IOTN index allows an easier evaluation since it possesses classification degrees established previously, in DHC and in AC. However, concerning the component aesthetic, also in aesthetic scale representative pictures of open biteand cross bite are not had, for instance, besides each individual's own subjectivity in analyzing her. A safeguard should bemade to DHC-IOTN that inhibits some characteristics once it only takes into account the most serious.

The importance of the patient's aesthetic perception regarding the orthodontic treatment cannot be underestimated. In other words, the patients that received treatment should al so be satisfied with the aesthetic and functional ben efits ${ }^{28}$. Based on this, the patients' opinion was evaluated and also compared regarding the reproducibility. Then, the patients were questioned in different moments and by different examiners. The data indicated that there was not a significant difference among the opinions of these patients to the two examiners. In other words, almost $100 \%$ of the patients agreed that there is a need for orthodontic treatment in relation to the two moments in that it was investigated. However, the reproducibility was not so relevant when the patient evaluated the aesthetic visual scale.

In relation to the reproducibility of the component AC of IOTN checked by the examiners, it was observed that the subjectivity of "perceiving" something similar in the scale of pictures it is minimized in the professionals' case, differently that what it happens with the patients that a lot of times appear for the picture that a situation that they would like to be or that they find to be the more aesthetics.

As it can be observed in Figures 1, 2, and 3 there was a clear tendency of the patients to indicate scores regarding without need of orthodon- tic treatment (from 1 to 4) when compared with the results obtained by the two examiners with theindexes DAI and DHC-IOTN, mainly. Therefore, these results corroborate the findings of Lewit ${ }^{26}$, which emphasized that the opinions of patients associated to theneed for treatment have been previously registered by the dental and facial appearance and the patients' complaint, this not al ways coincides with the professionals' evaluations in relation to the treatment need.

In this way, subsequent studies should be accomplished in different populations, with different needs for orthodontic treatment, with differentiated groups of orthodontists that allow a validation of these indexes in clinical different realities from those where they arose, in the sense of corroborating the discoveries of the present study.

\section{Conclusions}

According with theobtained data it could beconcluded that, regarding the reproducibility, both indexes were reproducible when comparing the data obtained by the two examiners. When evaluating, in decreasing order of reproducibility, which index was more reproducible in relation to the strips of treatment need the result obtained was DHC-IOTN, AC-IOTN and DAI. Therefore, the index IOTN was more reproducible than the index DAI. The two components of IOTN were reproducible, however, DHC was morethan $A C$, maybethis is explained by the subjectivity degree when evaluatetheaesthetic visual scaleof thecomponent AC.

\section{Collaborations}

PCA Paiva, ACR Farias and KC Lima have equally participated in every phase of the elaboration of this paper. 
1. Allen ND. Handicapping malocclusion assessment record in direct mouth examination. Am J Orthod 1970; 58:67-72.

2. Foster TD, Menezes DM. The assessment of occlusal features for public health planning purposes. Am J Orthod 1976; 69:83-90.

3. M iguel JAM. Estudo epidemiológico da severidade das más oclusões em escolares de 12 anos de idade da Rede M unicipal de Ensino do Rio de Janeiro [dissertação]. Rio de Janeiro (RJ): Faculdade de Odontologia, Universidade do Estado do Rio de Janeiro; 1998.

4. Calheiros AA. Avaliação dos resultados dos tratamentos realizados na clínica de Ortodontia da FO - UERJ [monografia]. Rio de Janeiro (RJ): Faculdade de Odontologia, Universidade do Estado do Rio de Janeiro, 1999.

5. Shaw WC, O'Brien KD, Richmond S. Quality control in orthodontics: Influencing the receipt of orthodontic treatment. Br Dent J 1991; 170(2):66-68.

6. Buchanan IB, Downing A, Stirrups DR. A comparison of the index of orthodontic treatment need applied clinically and to diagnostic records. $\mathrm{Br} J$ Orthod 1994; 21:185-188.

7. Keeling SD, M cGorray S, Wheeler T, King GJ. Imprecision in orthodontic diagnosis: Reliability of clinical measures of malocclusion. Angle Orthod 1996; 66(5):381-392.

8. Beglin FM, Firestone AR, Vig KW, Beck FM, Kuthy RA, Wade D. A comparison of the reliability and validity of 3 occlusal indexes of orthodontic treatment need. Am J Orthod Dentofacial Orthop 2001; 120(3):240-246.

9. Turner SA. Occlusal Index revisited. Br J Orthod 1990; 17(3):197-203.

10. Richmond S, Daniels CP. International comparisons of professional assessments in orthodontics: part I - treatment need. Am J Orthod Dentofacial Orthop 1998; 113:37-46.

11. Scivier GA, M enezes DM, Parker CD. A pilot study to assess the validity of the Orthodontic Treatment Priority Index in English schoolchildren. Community Dent Oral Epidemiol 1974; 2:246-252.

12. Sheats RD, McGorray SP, Keeling SD, Wheeler TT, King GJ. Occlusal traits and perception of orthodontic need in eighth grade students. Angle Orthod 1998; 68(2):107-114.

13. Emrich RE, Brodie AG, Blayney JR. Prevalence of Class I, Class II and Class III malocclusions (Angle) in an Urban Population. An epidemiological study. J Dent Res 1965; 44:947-953.

14. Angle EH. Classification of malocclusion. Dent. Cosmos 1899; 41:248-264.

15. Carlos JP. Evaluation of indexes of malocclusion Int Dent J 1970; 20:606-617.

16. Brook PH, Shaw WC. The development of an Index of orthodontic treatment priority. Eur J Orthod 1989; 11:309-320.
17. Cons NC, Jenny J, Kohout FJ, Songpaisan Y, Jotikastira D. Utility of the dental aesthetic index in industrialized and developing countries. J Pub Health Dent 1989; 49(3):163-166.

18. World Health Organization. Oral health surveys: basic methods. $4^{\text {th }}$ ed. Geneva: ORH/EPID; 1997.

19. Evans R, Shaw WC. Preliminary evaluation of an illustrated scale for rating dental attractiveness. Eur. J. Orthod.1987; 9:314-318.

20. Ecklund SA, M oller IJ, Leclercq M-H. Calibration of Examiners for Oral $\mathrm{H}$ ealth Epidemiological surveys. Geneva: WHO; 1993.

21. Richmond S, Shaw WC, O'Brien KD, Buchanan IB, Stephens $C D$, Andrews $M$, Roberts $C T$. The relationship between the index of orthodontic treatment need and consensus opinion of a panel of 74 dentists. Br Dent J 1995; 178:370-374.

22. Otuyemi OD, Noar JH. A comparison between DAI and SCAN in estimating orthodontic treatment need. Int Dent J 1996; 46(1):35-40.

23. Björk A, Krebs AA, Solow B. A method for epidemiological registration of malocclusion. Acta Odontol Scand 1964; 22(1):27-41.

24. Grainger RM. Orthodontic treatment priority index. Washington, D.C.: National Center for Health Statistics; 1967.

25. Salzmann JA. M alocclusion severity assessment. Am J Orthod 1967; 53(2):109-119.

26. Lewit DW, Virolainen K. Conformity and independence in adolescents' motivation for orthodontic treatment. Child Cev 1968; 39:189-200.

27. Summers CJ. The occlusal index: A system for identifying an scoring occlusal disorders. Am J Orthod 1971; 59(6):552-567.

28. Yeh MS, Koochek AR, Vlaslalic V, Boyd R, Richmond $\mathrm{S}$. The relationship of 2 professional occlusal indexes with patients' perceptions of aesthetics, function, speech, and orthodontic treatment need. Am J Orthod Dentofacial Orthop 2000; 118:421-428.

29. Beglin FM, Firestone AR, Vig KW, Beck FM, Kuthy RA, Wade D. Comparison of the reliability and validity of three occlusal index of orthodontic treatment need. Am J Orthod Dentofacial Orthop 2001; 120:240-246.

30. Tarvit DJ, Freer TJ. Assessing malocclusion - the time factor. Br J Orthod 1998; 25(1):31-34.

Artigo apresentado em 21/05/2007

Aprovado em 10/09/2007 